\title{
Landslide Susceptibility Mapping Using Different Modeling Approaches in Forested Areas (Sample of Çankırı-Yapraklı)
}

\author{
Ender Buğday
}

Çankırı Karatekin University, Faculty of Forestry, 18100 Çankırı, Turkey

\begin{abstract}
The effective management of forest resources is very important for the future of the forest and to meet both ecological and economic needs. In this study, it is aimed to contribute to the applicability of modeling in practice by identifying regions that may be landslide in forest areas via different modeling approaches. A total of six models were created by using four criteria (elevation, slope, aspect and stream power index) and using Fuzzy Inference System (FIS) and Modified-Analytic Hierarchy Process (M-AHP) approaches in this study. The model's performance was measured using the Receiver Operating Characteristic (ROC) curve and Area Under Curve (AUC). According to the results of study, the most successful model was determined as FIS Model 1 with the AUC value of $82.1 \%$ and M-AHP Model 1 with the AUC value of $80.9 \%$. This study provides important outputs that indicates the potential benefits of using landslide susceptibility mapping in the fields of forest harvesting, road network planning and forest management.
\end{abstract}

Keywords: Landslide, forest-planner, forest modeling

\section{Introduction}

Forestry activities consist of many sub-plans close relations with each other in a very wide area, such as forest harvesting planning, the road network planning, management planning. Forestry activities are multipurpose and multi-benefit oriented tasks. Forest is a limited natural resource, and re-forestation requires longterm efforts. Therefore, the effects of the factors that may have a negative impact on planning should be minimized. For this purpose, effective factors need to be effectively modeled. Today's technological opportunities provide a great advantage in creating fast and efficient modeling and decision support system. Modeling approaches are frequently used in forestry for various purposes such as landslide modeling in forested areas.

Many criteria can be used in the creation of landslide susceptibility mapping (LSM) models, such as elevation (Gokceoglu and Aksoy, 1996), distance to roads (Yesilnacar and Topal, 2005), land use (Fell et al., 2008), slope (Cevik and Topal, 2003), distance to faults (Pourghasemi et al., 2013), lithology (Van Westen et al., 2003), distance to streams (Ercanoglu and Gokceoglu, 2004), aspect (Yalcin, 2008), plan curvature (Regmi et al., 2014) and Stream Power Index (Jaafari et al., 2014).

There are many LSM modeling studies in the literature. The focus of these studies is the simultaneous evaluation of multiple factors. The studies differ in terms of modeling methods, such as Adaptive Neuro-Fuzzy Inference System (Sezer et al., 2017; Ghorbanzadeh et al., 2018), Analytical Hierarchy Process (Intarawichian and Dasananda, 2010; Quan and Lee, 2012), Artificial Neural Networks (Ermini et al., 2005; Park et al., 2013), Frequency Ratio (Pradhan, 2010; Park et al., 2013), Fuzzy Inference System (Park et al., 2012; Osna et al., 2014; Buğday and Özel, 2019), Logistic Regression (Lee 2005; Felicísimo et al., 2013), Machine Learning (Pradhan, 2013; Micheletti, 2014), Modified-Analytical Hierarchy Process (Sezer et al., 2017; Pourghasemi and Rossi, 2017), Random Forest (Youssef et al,. 2016; Catani et al., 2013) and Support Vector Machine (Özdemir and Altural, 2013; Pourghasemi et al., 2013).

Interpretation of results obtained from modeling studies and transferring them to planner and implementer by "susceptibility mapping" is quite common method (Yesilnacar and Topal, 2005; Pradhan, 2013). In this study, four models are presented according to two different modeling approaches for LSM in forest area. The landslide susceptibility map in the forest area was made by using elevation, slope, aspect and Stream Power Index factors, in order to create a basis for the planning of forestry activities, using Fuzzy Inference System (FIS) and Modified-Analytic Hierarchy Process (MAHP) approaches. Besides, various suggestions have 
been made for planner and practitioner in terms of the LSM using in forest area.

\section{Material and Methods}

\subsection{Study Area}

Yapraklı Forest Enterprise Chief (29407.3 ha) in Çankırı Forest Enterprise Directorate affiliated with Ankara Regional Directorate of Forestry was chosen a study area. This area is located between $40^{\circ} 47^{\prime} 10^{\prime \prime}-40^{\circ}$ $40^{\prime} 99^{\prime \prime}$ northern latitude and $33^{\circ} 35^{\prime} 01^{\prime \prime}-33^{\circ} 52^{\prime} 14^{\prime \prime}$ eastern longitude. Since there have been various landslides of various number and sizes in the study area, it has been used as research area in this study (Figure 1). The average slope of the study area is 12 degrees, the dominant aspect is the southeast and the average elevation is $1310 \mathrm{~m}$ (between $850 \mathrm{~m}$ and $1885 \mathrm{~m}$ ).

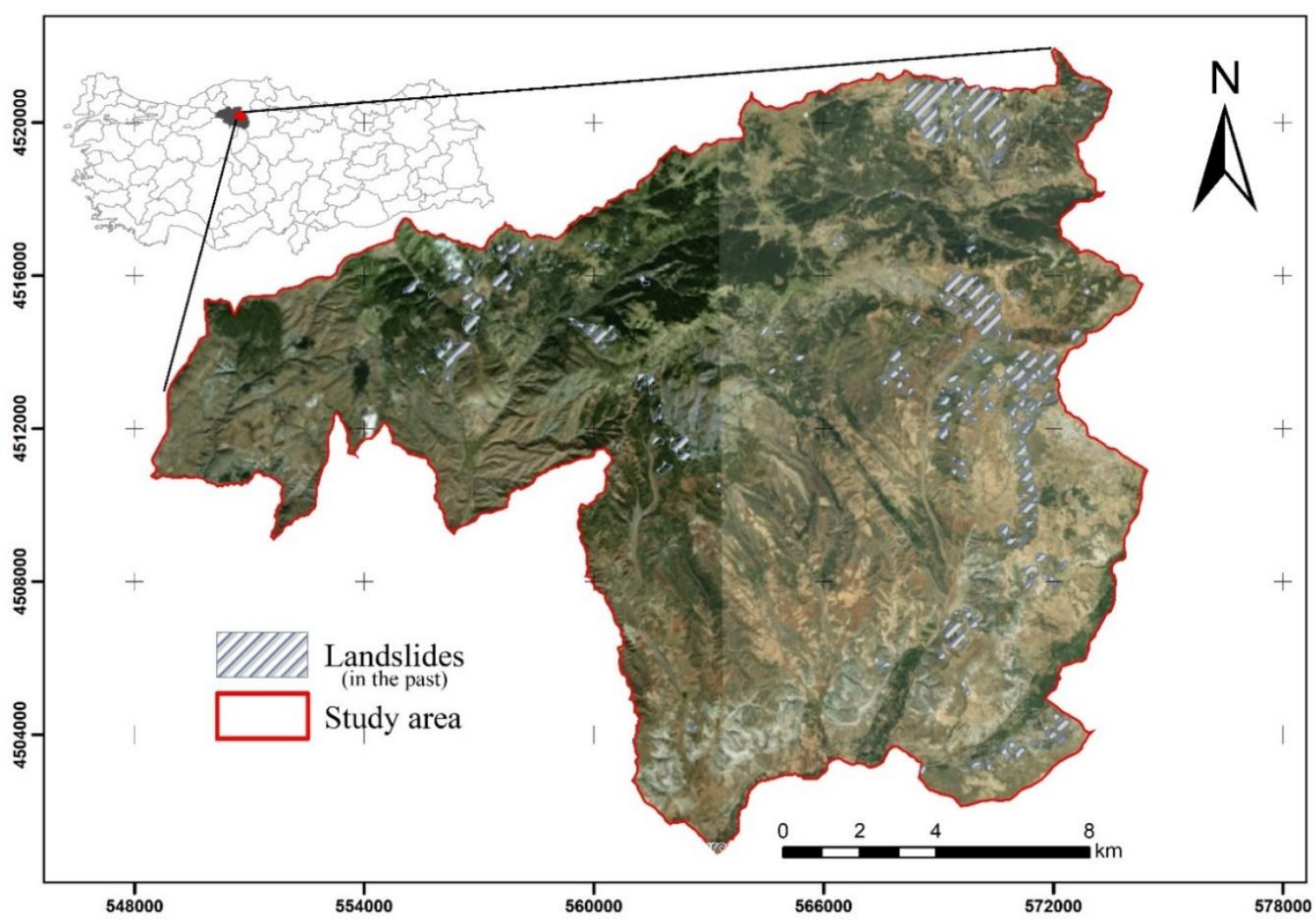

Figure 1 . The study area border and landslides

\subsection{Landslide Mapping}

The main objective of modeling studies is to achieve the highest success with minimum criteria (Agarwal and Rathod, 2006). In each LSM modeling study, combinations of different criteria are used. Many factors are used as criteria in LSM studies and there are no specific criteria that are widely used (Sahin et al., 2018). The characteristics of the study area and the quality of the available data can affect the success of the models created with different criteria combinations. The most important feature affecting these combinations is the availability of the data. This situation, which is to affect the success of the direct models, leads researchers to carry out modeling in different landslide areas using different criteria and their combinations. For these reasons, all criteria used in this study were obtained from ASTER - GDEM free of charge at $12.5 \mathrm{~m} \times 12.5 \mathrm{~m}$ high resolution (NASA, 2019). The criteria used in this study were elevation, slope, aspect and Stream Power Index (Figure 2).

The elevation is one of the most commonly used criteria in LSM studies. The average elevation in the study area was $1310 \mathrm{~m}$, with minimum elevation of $850 \mathrm{~m}$ and the maximum elevation of $1885 \mathrm{~m}$. In this study, the elevation was divided in five classes (850$1000 \mathrm{~m}, 1000-1150 \mathrm{~m}, 1150-1300 \mathrm{~m}, 1300-1500 \mathrm{~m}$, and 1500-1885 m).

Another important criteria is slope (degree) in LSM studies. The average slope of the study area was $14.33^{\circ}$, ranging from $0^{\circ}$ to $65.8^{\circ}$. In this study, the slope was classified into five different groups $\left(0-5^{\circ}, 5\right.$ $12^{\circ}, 12-18^{\circ}, 18-22^{\circ}$, and $\left.22-65.8^{\circ}\right)$.

The aspect factor is one of the factors included in such studies and it is generally classified in nine different groups (Flat, North, Northeast, East, South, Southeast, West, Northwest, and Southwest). The main aspect of the study area was the southeast aspect.

SPI (ranging from -1 to 17) is an index commonly used in LSM studies. SPI was used to express topography erosion (triggering landslides) based on the assumption that the basin area and current are proportional (Moore et al., 1991). 


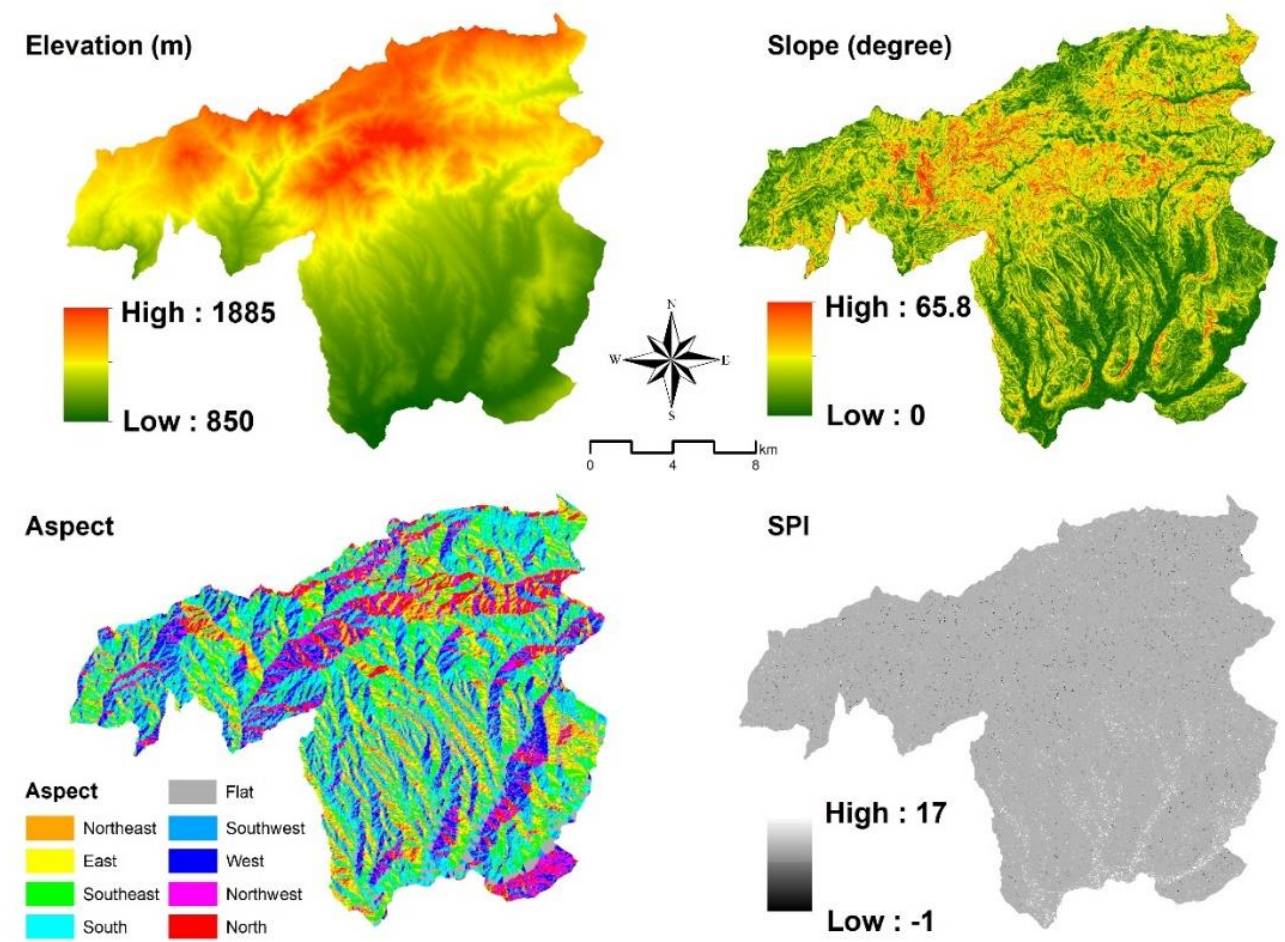

Figure 2. The criteria used in the study

The LSM process and the steps taken to generate the LSM in this study were given in the flow chart of Figure 3. This study consists of deciding of criteria, determination of modeling methods and validation, creation of models and evaluation of results.

The landslides locations and sizes (Duman et al., 2011) were gained from the General Directorate of Mineral Research and Exploration (MTA). The models were generated according to FIS and M-AHP approaches in this study. FIS is a commonly used approach to model simulation. The values of FIS are the values between 0 and 1 numbers, so the data for the criteria were normalized. In the FIS approach, membership functions are defined and learning rules are created. In this way, areas with landslide possibility are sorted from low to high sensitivity. The data obtained from the modeling were all converted to raster data format.

The M-AHP approach eliminates the user experience which is the main characteristic of the AHP approach (Sezer et al., 2017). The value of the criteria after being normalized and scored according to percentage of the landslides affecting the sensitivity was given in Table 1. The scores given to the factors were $1,3,5,7$ and 9. Then, these criteria were calculated in GIS and merged with each other to obtain models for LSM.

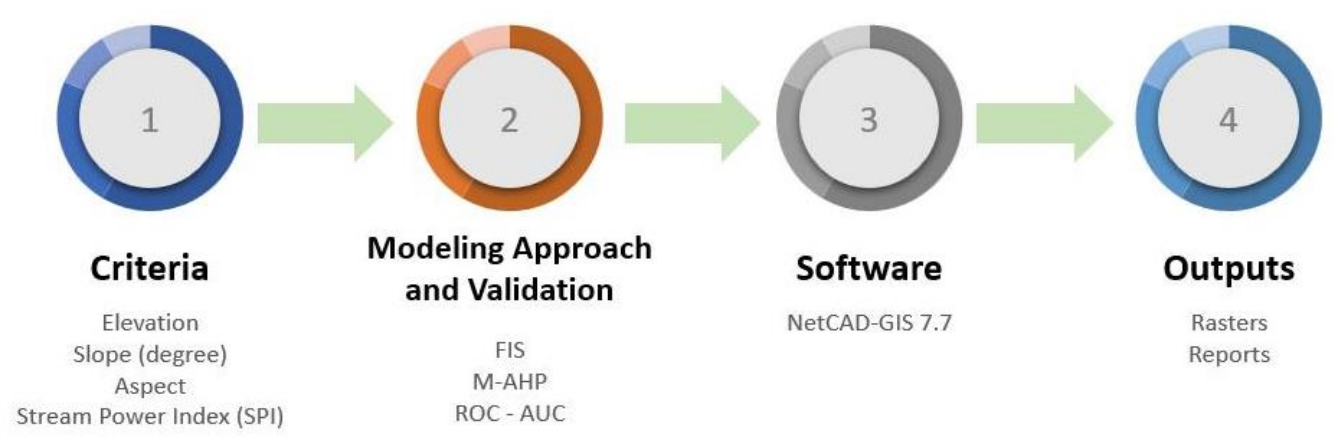

Figure 3. Flow chart of the study 
Table 1. Criteria group scores for M-AHP

\begin{tabular}{llcccc}
\hline Factors & Classes & Score & Factors & Classes & Score \\
\hline \multirow{4}{*}{ Elevation } & $850-1000$ & 1 & & $0-5$ & 1 \\
$(\mathrm{~m})$ & $1000-1150$ & 3 & & $5-12$ & 3 \\
& $1150-1300$ & 5 & Slope & $12-18$ & 5 \\
& $1300-1500$ & 7 & & $18-22$ & 7 \\
& $1500-1885$ & 9 & & $22-66$ & 9 \\
\hline \multirow{5}{*}{ Aspect } & Flat & 1 & & -1 & 9 \\
& North and Northwest & 3 & & 5 & 7 \\
& East, Northeast & 3 & SPI & 10 & 5 \\
& South and Southeast & 7 & & 13 & 3 \\
& West and Southwest & 5 & & 17 & 1 \\
\hline
\end{tabular}

In the study, two different models were formed by using four specified factors. The combinations of the factors used in the models were formed according to FIS and M-AHP approaches used in this study (Table 2).

Table 2. Combinations of factors used in models

\begin{tabular}{lll}
\hline Factors & Model 1 & Model 2 \\
\hline Elevation & $\checkmark$ & $\checkmark$ \\
Slope (degree) & $\checkmark$ & $\checkmark$ \\
Aspect & $\checkmark$ & $\checkmark$ \\
SPI & $\checkmark$ & - \\
\hline
\end{tabular}

The reliability of the models produced was tested with the Receiver Operating Characteristic (ROC) curve and the success rates of the models were calculated by the Area Under Curve (AUC). The ROC curve is generally used as the threshold value for binary classification systems as 0.50 (Nandi and Shakoor 2010). In this study, Netcad 7.7 software was used for implementations FIS and M-AHP approach, and ROC-AUC calculations.

\section{Results and Discussion}

According to the MTA landslide inventory, a total of 124 landslides occurred in the study area. The size of these landslides varied between a minimum of 0.2 ha and a maximum of 116 ha. The landslide sensitivity of the study area was relatively high. In this study, a total of four models have been developed (Figure 4). The value range varies between 0 and 0.8 in the developed FIS models. In M-AHP models, the values vary between 0 and 0.9 .
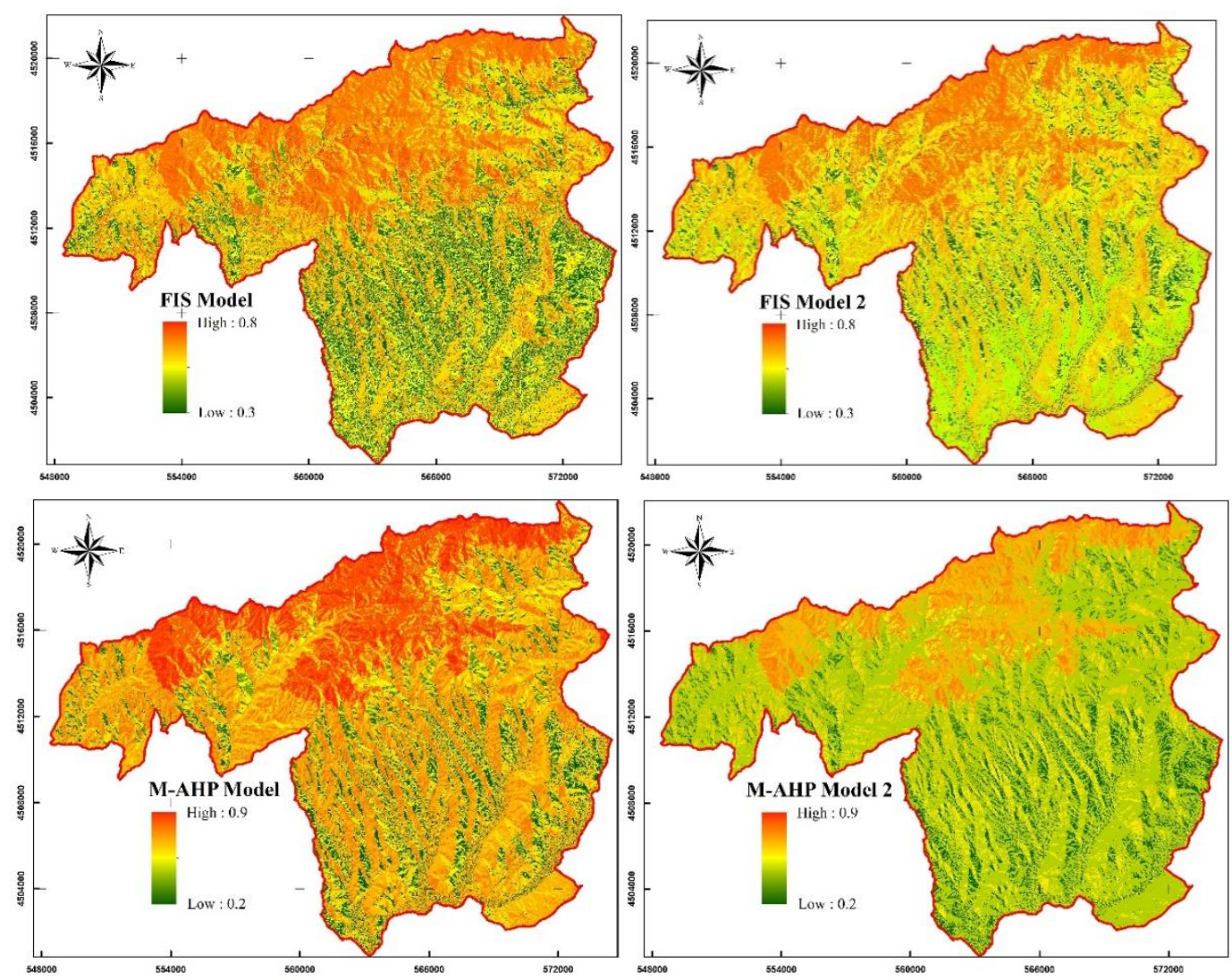

Figure 4. Model raster outputs (FIS and M-AHP) 
For modeling validation, past landslides have been used. Models were tested with ROC and success rates were determined with AUC. According to this; FIS Model 1 AUC $=82.1 \%$ and FIS Model 2 AUC $=79.8 \%$, M-AHP Model 1 AUC $=80.9 \%$ and M-AHP Model 2 $\mathrm{AUC}=78.3 \%$ (Figure 5).

In this study, the modelling approach using of advanced GIS methods to create a decision support platform in planning before the forestry activities in
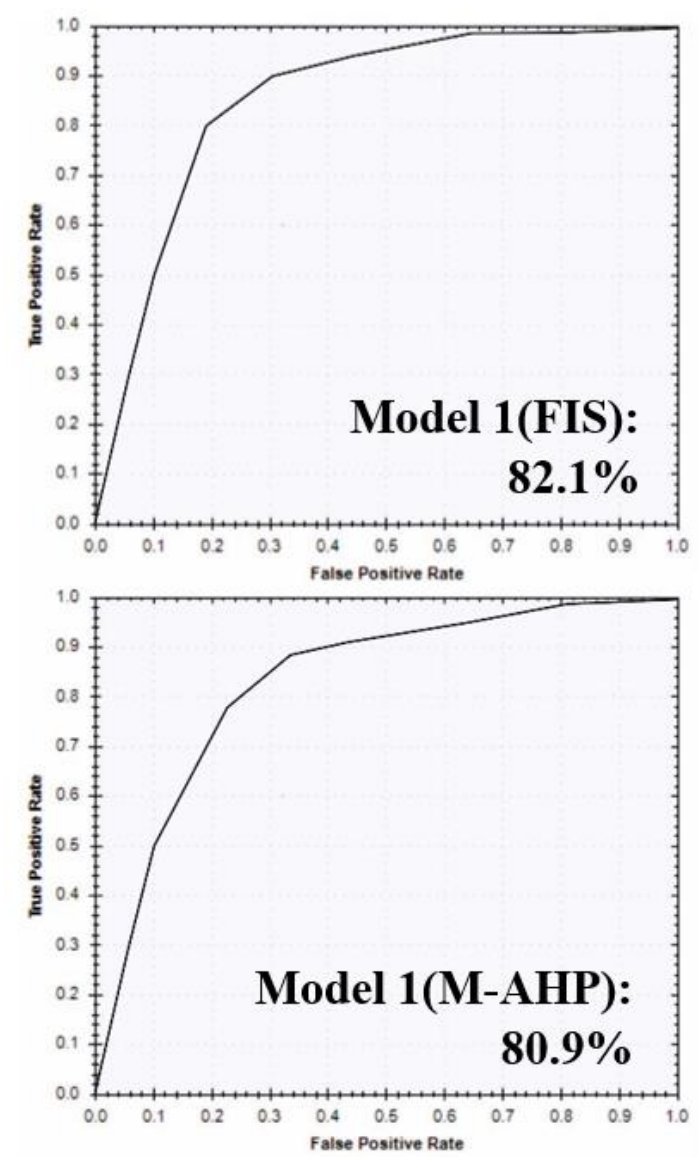

Figure 5. AUC success values of the Models the landslide sensitive forest areas was carried out. Four criteria were used in this study and four different models were obtained. It was found that FIS and MAHP approaches can be preferred since they have practical use for planners and practitioners. The most successful model was Model 1 (AUC=82.1\%) obtained by the FIS approach. In Model 2, a lower success rate was achieved due to three criteria.
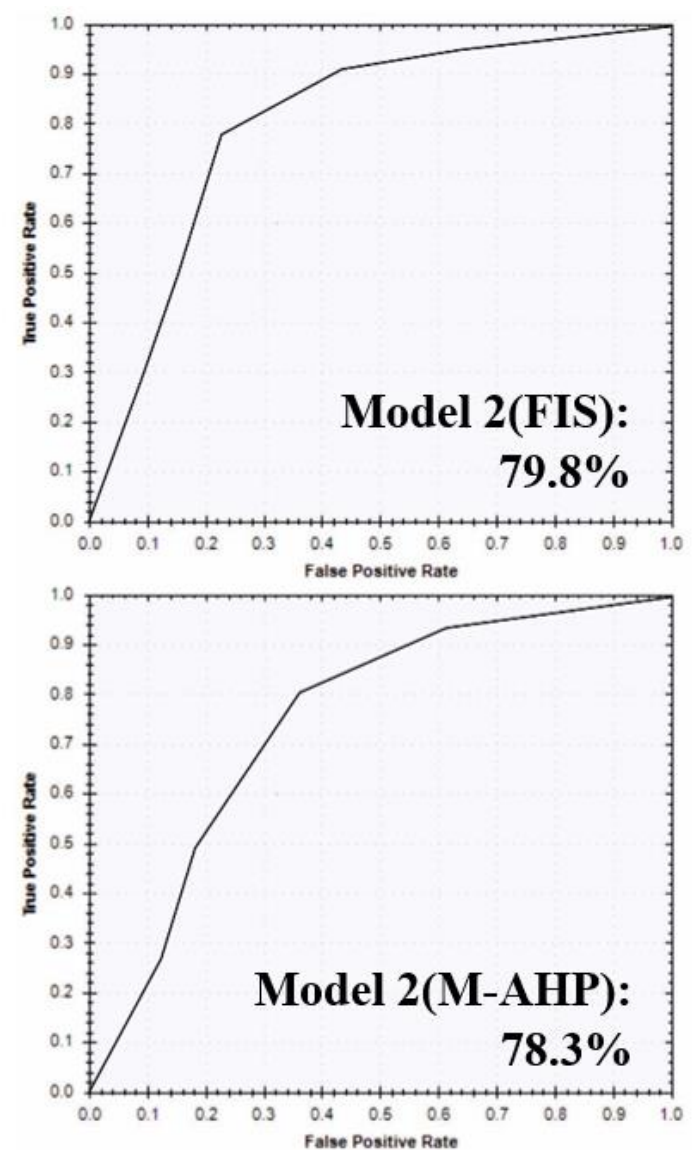

The models created by FIS provided more successful results than M-AHP models in this study. In a similar study conducted by Sezer et al. 2017, using FIS and M-AHP approaches (seven factors), it was reported that AUC values ranged between 0.66 and 0.82 . Buğday and Özel (2019) conducted a study using FIS and M-AHP (nine factors) and they found that AUC values ranged between 0.62 and 0.71 . The values obtained from these studies were similar to the analysis results in this study.

\section{Conclusion}

In forestry activities carried out according to the principles of sustainable forest management, planning is even more important than before. Knowing the negative impacts that will affect the success of planning, identifying and modeling the possible impacts increases the success and applicability of planning. In this study, the factor of the landslide which has a negative impact on planning in forestry applications in landslide sensitive areas was effectively modeled considering slope, aspect, elevation, and SPI criteria. In the follow up studies; the most suitable modeling methods can be determined for forestry applications by evaluating different criteria and models in landslide sensitive forest areas.

\section{References}

Agarwal, N., Rathod, U., 2006. Defining 'success' for software projects: An exploratory revelation. International Journal of Project Management, 24(4): 358-370.

Buğday, E., Özel, H.B., 2019. Utilizing a fuzzy inference system (FIS) and modified analytical hierarchical analysis for forest road network planning in afforested lands. Polish Journal of Environmental Studies, 28(3):1579-1589. https://doi.org/10.15244/pjoes/89611.

Catani, F., Lagomarsino, D., Segoni, S., Tofani, V., 2013. Landslide susceptibility estimation by 
random forests technique: sensitivity and scaling issues. Natural Hazards and Earth System Sciences, 13(11):2815-2831.

Cevik, E., Topal, T., 2003. GIS-based landslide susceptibility mapping for a problematic segment of the natural gas pipeline, Hendek (Turkey). Environmental Geology, 44(8) 949-962.

Duman, T.Y., Çan, T., Emre, Ö., 2011. 1/1.500.000 Turkey landslide inventory map, General Directorate of Mineral Research and Exploration, Special Publications Series, No: 27, Ankara, Turkey. ISBN: 978-605-4075-85-3.

Ercanoglu, M., Gokceoglu, C., 2004. Use of fuzzy relations to produce landslide susceptibility map of a landslide prone area (West Black Sea Region, Turkey). Engineering Geology, 75(3-4), 229-250.

Ermini, L., Catani, F., Casagli, N., 2005. Artificial neural networks applied to landslide susceptibility assessment. Geomorphology, 66(1-4):327-343.

Felicísimo, Á.M., Cuartero, A., Remondo, J., Quirós, E., 2013. Mapping landslide susceptibility with logistic regression, multiple adaptive regression splines, classification and regression trees, and maximum entropy methods: a comparative study. Landslides, 10(2):175-189.

Fell, R., Corominas, J., Bonnard, C., Cascini, L., Leroi, E., Savage, W. Z., 2008. Guidelines for landslide susceptibility, hazard and risk zoning for land-use planning. Engineering Geology, 102(3-4): 99-111.

Ghorbanzadeh, O., Blaschke, T., Aryal, J., Gholaminia, K., 2018. A new GIS-based technique using an adaptive neuro-fuzzy inference system for land subsidence susceptibility mapping. Journal of Spatial Science, 1-17.

Gokceoglu, C. Aksoy, H. 1996. Landslide susceptibility mapping of the slopes in the residual soils of the Mengen region (Turkey) by deterministic stability analyses and image processing techniques. Engineering Geology, 44:147-161.

Intarawichian, N., Dasananda, S., 2010. Analytical hierarchy process for landslide susceptibility mapping in lower Mae Chaem watershed, northern Thailand. Suranaree Journal of Science \& Technology, 17(3).

Jaafari, A., Najafi, A., Pourghasemi, H. R., Rezaeian, J., Sattarian, A., 2014. GIS-based frequency ratio and index of entropy models for landslide susceptibility assessment in the Caspian forest, northern Iran. International Journal of Environmental Science and Technology, 11(4): 909-926.

Lee, S., 2005. Application of logistic regression model and its validation for landslide susceptibility mapping using GIS and remote sensing data. International Journal of Remote Sensing, 26(7): 1477-1491.
Micheletti, N., Foresti, L., Robert, S., Leuenberger, M., Pedrazzini, A., Jaboyedoff, M., Kanevski, M., 2014. Machine learning feature selection methods for landslide susceptibility mapping. Mathematical Geosciences, 46(1):33-57.

Moore, I.D., Grayson, R.B., Ladson, A. R. 1991. Digital terrain modelling: A review of hydrological, geomorphological, and biological applications. Hydrological Processes, 5(1), 3-30.

Nandi, A., Shakoor, A., 2010. A GIS-based landslide susceptibility evaluation using bivariate and multivariate statistical analyses. Engineering Geology, 110(1-2):11-20.

NASA, 2019. https://asterweb.jpl.nasa.gov/data.asp. Access date: 16/04/2019

Osna, T., Sezer, E. A., Akgun, A., 2014. GeoFIS: an integrated tool for the assessment of landslide susceptibility. Computers \& Geosciences, 66:2030.

Özdemir, A., Altural, T. 2013. A comparative study of frequency ratio, weights of evidence and logistic regression methods for landslide susceptibility mapping: Sultan Mountains, SW Turkey. Journal of Asian Earth Sciences, 64:180-197.

Park, I., Choi, J., Lee, M. J., Lee, S., 2012. Application of an adaptive neuro-fuzzy inference system to ground subsidence hazard mapping. Computers \& Geosciences, 48:228-238.

Park, S., Choi, C., Kim, B., Kim, J., 2013. Landslide susceptibility mapping using frequency ratio, analytic hierarchy process, logistic regression, and artificial neural network methods at the Inje area, Korea. Environmental Earth Sciences, 68(5): 1443-1464.

Pourghasemi, H.R., Jirandeh, A.G., Pradhan, B., Xu, C., Gokceoglu, C., 2013. Landslide susceptibility mapping using support vector machine and GIS at the Golestan Province, Iran. Journal of Earth System Science, 122(2), 349-369.

Pourghasemi, H.R., Rossi, M., 2017. Landslide susceptibility modeling in a landslide prone area in Mazandarn Province, north of Iran: a comparison between GLM, GAM, MARS, and M-AHP methods. Theoretical and Applied Climatology, 130(1-2):609-633.

Pradhan, B., 2010. Landslide susceptibility mapping of a catchment area using frequency ratio, fuzzy logic and multivariate logistic regression approaches. Journal of the Indian Society of Remote Sensing, 38(2):301-320.

Pradhan, B., 2013. A comparative study on the predictive ability of the decision tree, support vector machine and neuro-fuzzy models in landslide susceptibility mapping using GIS. Computers \& Geosciences, 51:350-365.

Quan, H.C., Lee, B.G., 2012. GIS-based landslide susceptibility mapping using analytic hierarchy process and artificial neural network in Jeju 
(Korea). KSCE Journal of Civil Engineering, 16(7):1258-1266.

Regmi, A.D., Devkota, K.C., Yoshida, K., Pradhan, B., Pourghasemi, H. R., Kumamoto, T., Akgun, A., 2014. Application of frequency ratio, statistical index, and weights-of-evidence models and their comparison in landslide susceptibility mapping in Central Nepal Himalaya. Arabian Journal of Geosciences, 7(2), 725-742.

Sahin, E.K., Colkesen, I., Kavzoglu, T., 2018. A comparative assessment of canonical correlation forest, random forest, rotation forest and logistic regression methods for landslide susceptibility mapping. Geocarto International, 1-23.

Sezer, E.A., Nefeslioglu, H.A., Osna, T., 2017. An expert-based landslide susceptibility mapping (LSM) module developed for Netcad architect software. Computers \& Geosciences, 98:26-37.

Van Westen, C.J., Rengers, N., Soeters, R., 2003. Use of geomorphological information in indirect landslide susceptibility assessment. Natural Hazards, 30(3):399-419.

Yalcin, A., 2008. GIS-based landslide susceptibility mapping using analytical hierarchy process and bivariate statistics in Ardesen (Turkey): comparisons of results and confirmations. Catena, 72(1):1-12.

Yesilnacar, E., Topal, T., 2005. Landslide susceptibility mapping: a comparison of logistic regression and neural networks methods in a medium scale study, Hendek region (Turkey). Engineering Geology, 79(3-4):251-266.

Youssef, A. M., Pourghasemi, H.R., Pourtaghi, Z.S., Al-Katheeri, M. M., 2016. Landslide susceptibility mapping using random forest, boosted regression tree, classification and regression tree, and general linear models and comparison of their performance at Wadi Tayyah Basin, Asir Region, Saudi Arabia. Landslides, 13(5):839-856. 